\title{
Role of local anaesthetic nerve block in patients undergoing endonasal surgery - our experience of 48 patients*
}

\author{
Eamon Shamil', Elizabeth Casselden'1, Florian Bast ${ }^{1}$, Will Whiteley²， Rhinology Online, vol 1:90-93, 2018 \\ Claire Hopkins' ${ }^{1}$, Pavol Surda' \\ http://doi.org/10.4193/RHINOL/18.033 \\ ENT Department, Guy's and St Thomas'NHS Foundation Trust, London, United Kingdom \\ *Received for publication: \\ 2 Department of Anaesthesia, Guy's and St Thomas' NHS Foundation Trust, London, United Kingdom \\ July 8, 2018 \\ Accepted: August 13, 2018 \\ Published: August 27, 2018
}

\begin{abstract}
Objective: This study examines the effect of preoperative AEN block and SPG nerve block with $0.5 \%$ bupivacaine and 1:200,000 adrenaline (LA) on postoperative pain in patients undergoing endonasal surgery.

Study design: This is non-randomised and partly blinded study of 48 patients undergoing ESS. 30 patients underwent pre-operative SPG and AEN local anaesthetic blockade and remaining 18 patients served as controls.

Results: The pain score at 1, 2 and 3 hours after the surgery in local anaesthetic vs. control group was 1.1 vs. 2.8 ( $p<0.001), 1.4$ vs $3.4(p<0.001)$ and 1.7 vs $3.5(p<0.001)$, respectively. The most significant difference of 1.94 points $(p<0.001)$ on the VAS scale was seen at 2 hours. No complications were observed in either group.

Conclusion: Our results have indicated that there is a significant reduction in the first three hours of post-operative pain after endonasal surgery in patients who underwent blockage of these nerves, compared to a control group. However, this study was neither randomised nor blinded and sample size was small. Further study in the form of larger randomised trial is therefore needed.
\end{abstract}

Key words: pterygopalatine ganglion block, nerve block, postoperative pain

\section{Introduction}

Regional nerve blockade using local anaesthetic before endonasal surgery may reduce postoperative pain ${ }^{(1-4)}$. We aim to assess the effect of preoperative anterior ethmoidal nerve (AEN) block and sphenopalatine ganglion (SPG) nerve block with $0.5 \%$ bupivacaine and 1:200,000 adrenaline local anaesthetic (LA) on postoperative pain in patients undergoing endonasal surgery.

\section{Materials and methods}

Of 48 patients listed for endonasal surgery, 30 underwent preoperative SPG and AEN local anaesthetic blockade. Prior to the surgery, all participants in the nerve block group were informed about the intervention. However, nursing staff in recovery was not informed, thus the design was partly blinded.

The remaining 18 patients who didn't receive nerve block were analysed retrospectively and served as controls. We routinely collect the pain scores in recovery unit as a part of postoperative observations, therefore we made a comparison to see if the introduction of technique led to the improvement of care. All procedures took place at Guy's Hospital, London, UK by a single consultant surgeon. This technique had always been his practice in his previous hospital and was introduced after the discussion with anaesthetist.

Inclusion criteria were: chronic rhinosinusitis with or without po- 
lyps, septal deviation and/or inferior turbinate swelling causing nasal blockage, in patients of ASA grade 1-2, aged over 18 years, in whom nasal surgery is indicated due to failure of medical treatment. We excluded patients with pre-existing chronic facial pain of other aetiology and/or taking regular analgesia and/or antidepressant and/or antiepileptic medications.

\section{Technique}

Standardised anaesthesia was induced by intravenously administering 4-8mcg/ml propofol and 4-8ng/ml remifentanil. After insertion of laryngeal mask airway, the nasal cavity was irrigated with Moffet's solution ( $1 \mathrm{ml}$ cocaine hydrochloride $10 \%, 1 \mathrm{ml}$ adrenaline $1: 1000,2 \mathrm{ml}$ sodium bicarbonate $8.4 \%, 6 \mathrm{ml}$ sodium chloride $0.9 \%$ ) to ensure adequate decongestion.

After induction of anaesthesia, the transoral SPG and endonasal AEN blocks were performed. The 25-gauge needle was bent 25 $\mathrm{mm}$ from the tip at a $45^{\circ}$ angle to ensure safe and effective delivery of $2 \mathrm{ml} L A$. The needle was inserted into the greater palatine foramen, traversing the greater palatine canal into the pterygopalatine fossa ${ }^{(5)}$. AEN block was performed by endoscopic endonasal submucosal infiltration of the agger nasi cell and middle turbinate region with $1 \mathrm{ml}$ of $\mathrm{LA}$, which achieves blockade of the anterior lateral nasal branch of the nerve.

Postoperatively, all patients were prescribed analgesia as per hospital protocol until discharged: $1 \mathrm{~g}$ oral paracetamol, 30 mg dihydrocodeine. Fentanyl was used as a rescue analgesia if required.

The patients were asked to rate their pain post operatively at 1,2 and 3 hours using visual analogue scale (VAS) $(0=$ no pain, $10=$ most severe pain).

\section{Outcome measures and statistical analysis}

Data were collected regarding patient demographics and operative procedure. The primary outcome measure was the difference in postoperative pain (graded on a $10-\mathrm{cm}$ visual analogue scale) at 1, 2, and 3 hours after the surgery between subjects with nerve blockades and controls. We did not measure blood loss or the quality of the surgical field. The Kolmogorov-Smirnov test showed normal distribution. The differences in postoperative pain were analysed with Student's T-test (SPSS Inc., Chicago, IL, USA). Results were considered as significant at the $p \leq 0.05$ level.

\section{Results}

All 48 participants completed the study. Procedures undertaken were FESS [29], septoplasty and cold-steel turbinoplasty as one procedure [13], septoplasty alone [3], cold-steel turbinoplasty alone [2] and bilateral SPA ligation (which involved a middle
Table 1. Patient demographic and intraoperative details. Characteristics of nerve blockage intervention group versus control group including operation, revision surgery status, sex and age.

\begin{tabular}{|c|c|c|}
\hline & $\begin{array}{l}\text { Nerve block group } \\
(n=30)\end{array}$ & $\begin{array}{l}\text { Control group } \\
\qquad(n=18)\end{array}$ \\
\hline Average age & 42 & 38 \\
\hline \multicolumn{3}{|l|}{ Gender (n) } \\
\hline Female & $8(16.7 \%)$ & $6(12.5 \%)$ \\
\hline Male & $22(45.8 \%)$ & $12(25 \%)$ \\
\hline FESS (n) & 19 (39.6\%) & $10(20.1 \%)$ \\
\hline Primary FESS (n) & $13(27.1 \%)$ & $3(6.25 \%)$ \\
\hline Revision FESS (n) & $6(12.5 \%)$ & $7(14.6 \%)$ \\
\hline $\begin{array}{l}\text { Septoplasty + } \\
\text { turbinoplasty (n) }\end{array}$ & $6(12.5 \%)$ & $7(14.6 \%)$ \\
\hline Turbinoplasty (n) & $2(4.2 \%)$ & 0 \\
\hline Septoplasty (n) & $2(4.2 \%)$ & $1(2.1 \%)$ \\
\hline SPA ligation (n) & $1(2.1 \%)$ & 0 \\
\hline
\end{tabular}

FESS = functional endoscopic sinus surgery, SPA= sphenopalatine artery ligation.

meatal antrostomy as part of the approach) [1]. None of the patients needed rescue analgesia. The participants' mean age in the "block" group was 42 years ranging from 24 to 71 years and the mean age of controls was 38 ranging from 19 to 71 years. Other respondents' characteristics are shown in Table 1. Table 2 shows the mean VAS score at all three-measured time points for the LA and control arms. Low levels of pain were observed in both groups however the scores were lower at each time point in patients receiving LA nerve blockade. The pain score at 1 , 2 and 3 hours after the surgery in local anaesthetic vs. control group was 1.1 vs. $2.8(p<0.001), 1.4$ vs $3.4(p<0.001)$ and 1.7 vs 3.5 ( $p<0.001$ ), respectively (Table 2.). The most significant difference of 1.94 points $(p<0.001)$ on the VAS scale was seen at 2 hours. Subgroup analysis demonstrated similar results. If we set the minimal clinically important difference (MCID) to $1.3 \mathrm{~cm}{ }^{(6)}$, all results reached statistical and clinical significance. For further details see Table 3 and 4 . No complications were observed in either group.

In summary, the difference in mean VAS score between the two groups showed a high level of statistical significance under 2-tailed t-tests, at all three measured timepoints. Confidence intervals between the two groups at all three time points did not overlap, further reinforcing the significance of our results.

\section{Discussion}

The SPG and the AEN contribute to the main neurological supply of the nasal cavity ${ }^{(7)}$. Bupivacaine is a LA that works by 
Table 2. Postoperative pain scores in both groups ${ }^{*}$ Comparison of pain levels 1-3 hours postoperatively in nerve blockade intervention group with control group.

\begin{tabular}{|cccc|}
$\begin{array}{c}\text { Time After } \\
\text { Surgery (Hrs) }\end{array}$ & $\begin{array}{c}\text { Nerve } \\
\text { Blockade } \\
\text { Group }(\mathbf{n = 3 0 )} \\
(\mathbf{9 5} \% \mathrm{CI})\end{array}$ & $\begin{array}{c}\text { Control Group } \\
(\mathbf{n = 1 8}) \\
(\mathbf{9 5} \% \mathrm{CI})\end{array}$ & P-Value \\
\hline 1 & $1.1(0.99-1.21)$ & $2.8(2.37-3.17)$ & $\mathrm{p}<0.001$ \\
\hline 2 & $1.4(1.28-1.62)$ & $3.4(2.95-3.81)$ & $\mathrm{p}<0.001$ \\
\hline 3 & $1.7(1.49-1.90)$ & $3.5(2.88-4.10)$ & $\mathrm{p}<0.001$ \\
\hline
\end{tabular}

*Values are mean. $\mathrm{Cl}=$ confidence interval.

Table 3. Subgroup analysis of postoperative pain scores in FESS groups* Comparison of pain levels 1-3 hours postoperatively in nerve blockade intervention group with control group.

\begin{tabular}{|lccc|}
\hline $\begin{array}{c}\text { Time After } \\
\text { Surgery (Hrs) }\end{array}$ & $\begin{array}{c}\text { Nerve } \\
\text { Blockade } \\
\text { Group }(\mathbf{n = 1 9 )} \\
(\mathbf{9 5} \% \mathrm{Cl})\end{array}$ & $\begin{array}{c}\text { Control Group } \\
(\mathbf{n = 1 0 )} \\
(\mathbf{9 5 \%} \mathrm{Cl})\end{array}$ & P-Value \\
\hline 1 & $1.1(1.00-1.28)$ & $2.62(2.03-3.21)$ & $\mathrm{p}<0.001$ \\
\hline 2 & $1.5(1.27-1.73)$ & $3.28(2.61-3.95)$ & $\mathrm{p}<0.001$ \\
\hline 3 & $1.7(1.44-2.00)$ & $3.26(2.39-4.13)$ & $\mathrm{p}<0.001$ \\
\hline
\end{tabular}

*Values are mean. $\mathrm{Cl}=$ confidence interval.

Table 4. Subgroup analysis of postoperative pain scores in septoplasty groups* Comparison of pain levels 1-3 hours postoperatively in nerve blockade intervention group with control group.

\begin{tabular}{|lccc|}
\hline $\begin{array}{c}\text { Time After } \\
\text { Surgery (Hrs) }\end{array}$ & $\begin{array}{c}\text { Nerve } \\
\text { Blockade } \\
\text { Group } \\
(95 \% \mathrm{Cl})\end{array}$ & $\begin{array}{c}\text { Control Group } \\
(95 \% \mathrm{CI})\end{array}$ & P-Value \\
\hline 1 & $1.0(0.78-1.31)$ & $2.96(2.30-3.61)$ & $\mathrm{p}<0.001$ \\
\hline 2 & $1.3(0.90-1.73)$ & $3.54(2.90-4.20)$ & $\mathrm{p}<0.001$ \\
\hline 3 & $1.6(1.14-2.01)$ & $3.81(2.72-4.90)$ & $\mathrm{p}<0.002$ \\
\hline
\end{tabular}

*Values are mean. $\mathrm{Cl}=$ confidence interval.

increasing the threshold for electrical excitation in nerve membranes and hence blocking propagation of action potentials and the conduction of nervous impulses. Dilute adrenaline reduces the absorption and prolongs the duration of action. It is thought that bupivacaine has an onset of around 2-10 minutes, and can last up to 7 hours; this will be prolonged with the addition of adrenaline ${ }^{(8-10)}$.

\section{Key points}

Our results have indicated that there is a significant reduction in the first three hours of post-operative pain after endonasal surgery in patients who underwent blockage of these nerves, compared to a control group.

\section{Comparisons with other studies}

To date, randomised control trials studying similar techniques have produced conflicting results regarding the effect of preemptive anaesthesia on postoperative pain ${ }^{(3,11,12)}$. Postoperative pain was also a subject of other study which showed positive effect of cold application following septorhinoplasty on reduction of pain scores ${ }^{(13)}$. However, there is no article in the literature describing the effect of transoral injection of SPG in combination with AEN block. Moreover, recent systematic review showed that there is a considerable heterogeneity of current studies describing the effect of pre-emptive anaesthesia in ESS ${ }^{(4)}$. This study adds to the body of evidence that these techniques are effective.

\section{Limitations of this study}

Major limitation of the study is the non-randomised design, which may lead to selection bias. This was minimised by the selection of patients in the consecutive order. Other limitations include small sample size and lack of blinding in the nerve block group as explained in methods.

Postoperative consumption of analgesia was the major confounder in the study. Although we have not measured the exact administered amounts of standard analgesia (paracetamol, dihydrocodeine), none of the patients needed the rescue pain relief (fentanyl).

\section{Clinical applicability of the study}

Future studies will assess whether regional nerve blockage reduces the need for postoperative analgesia and its associated adverse effects. Improved postoperative pain control is likely to enhance recovery and facilitate early discharge. This pilot suggests the need for a larger randomised trial to confirm our preliminary findings.

\section{Ethics approval and consent to participate}

This study served as an evaluation of practice and was approved by Guy's Hospital Clinical Governance Department.

\section{Authorship contribution}

ES: writing the paper, collection of data, data analysis; EC: data analysis; FB: collection of data; WW: design of anaesthetic protocol, writing the paper; $\mathrm{CH}$ : collection of data, writing the paper; PS: design, collection of data and analysis, writing the paper. 


\section{Availability of data and materials}

The datasets used and/or analysed during the current study are available from the corresponding author on reasonable request.

\section{Conflict of interest}

The authors declare that they have no competing interests.

\section{References}

1. Cho D-Y, Drover DR, Nekhendzy V, Butwick AJ, Collins J, Hwang PH. The effectiveness of preemptive sphenopalatine ganglion block on postoperative pain and functional outcomes after functional endoscopic sinus surgery. Int Forum Allergy Rhinol. 2011;1(3):212-8.

2. Cohen-Kerem R, Brown S, Villaseñor LV Witterick I. Epinephrine/Lidocaine Injection Vs. Saline During Endoscopic Sinus Surgery. Laryngoscope. 2008;118(7):1275-81.

3. Al-Qudah M. Endoscopic sphenopalatine ganglion blockade efficacy in pain contro after endoscopic sinus surgery. Int Forum Allergy Rhinol. 2015;6(3):334-8.

4. Shamil E, Rouhani MJ, Basetti S, Bast F, Hopkins C, Surda P. Role of local anaesthetic nerve block in endoscopic sinus surgery: A systematic review and meta-analysis. Clin Otolaryngol. 2018.

5. Douglas R, Wormald P-J. Pterygopalatine Fossa Infiltration Through the Greater Palatine Foramen: Where to Bend the
Needle. Laryngoscope. 2006;116(7):1255-7.

6. Todd $\mathrm{KH}$. Clinical versus statistical significance in the assessment of pain relief. Ann Emerg Med. 1996;27(4):439-41.

7. Sinnatamby CS. Last's Anatomy Regional and Applied, 9th ed.: Churchill; 2003.

8. Friedman $M$, Venkatesan TK, Lang $D$, Caldarelli DD. Bupivacaine for Postoperative Analgesia Following Endoscopic Sinus Surgery. Laryngoscope. 1996;106(11):13825.

9. Bernards CM, Kopacz DJ. Effect of Epinephrine on Lidocaine Clearance In Vivo. Anesthesiology. 1999;91(4):962.

10. Becker DE, Reed KL. Local Anesthetics: Review of Pharmacological Considerations. Anesth Prog. 2012;59(2):90-102.

11. DeMaria S, Govindaraj S, Chinosorvatana N Kang S, Levine Al. Bilateral Sphenopalatine Ganglion Blockade Improves Postoperative Analgesia after Endoscopic Sinus Surgery. Am J Rhinol Allergy. 2012;26(1):e23-e7.

12. Kesimci E, Ozturk L, Bercin S, Kiris M, Eldem A, Kanbak O. Role of sphenopalatine gan- glion block for postoperative analgesia after functional endoscopic sinus surgery. Eur Arch Otorhinolaryngol. 2012;269(1):165-9.

13. Kayiran O, Calli C. The effect of periorbital cooling on pain, edema and ecchymosis after rhinoplasty: a randomized, controlled, observer-blinded study. Rhinology. 2016;54(1):32-7

Mr Eamon Shamil

ENT Department

Guy's and St Thomas'

NHS Foundation Trust

London United Kingdom

E-mail: eamonshamil@gmail.com 